AJIE - Asian Journal of Innovation and Entrepreneurship

(e-ISSN: 2477- 0574; p-ISSN: 2477-3824)

Vol. 01, No. 01, January 2016

\title{
IbM PRODUK HERBAL DI UKM LAWU HERBAL DAN UKM PONDOK DAUN HERBAL
}

\author{
Aulia Qonita ${ }^{1}$ and Nur Her Riyadi Parnanto ${ }^{2}$ \\ ${ }^{1}$ Agribisnis, Fakultas Pertanian, Universitas Sebelas Maret, Surakarta, Indonesia \\ ${ }^{2}$ Teknologi Pertanian Ilmu Jurusan, Fakultas Pertanian, Universitas Sebelas Maret, Surakarta, Indonesia \\ E-mail: auliaqonita@yahoo.co.id
}

\begin{abstract}
This activity is carried out in SMEs Lawu Herbal UKM in Mawar Street No 03. Dimoro RT 02 RW 10 Karanganyar village, District of Karanganyar and SMEs Pondok Daun in Rajawali Street No. 8, Ngebrak RT 01 / XI, Gentan, Baki, Sukoharjo. This activity aims to provide solutions of problems which is faced by SMEs. The problem faced by SMEs Lawu Herbal is a simple plastic packaging is still using ordinary sealer system; marketing still limited and not use the media website. The problem is faced by SMEs Pondok Daun Herbal is the unavailability of neat book keeping. This activities carried out by the introduction of vacuum sealer tools, marketing training through the website and the training of financial accounting and management improvements.

Results from service activities are 1) the packaging of products in SMEs Lawu Herbal become better, more durable and fresh, 2) SMEs Lawu Herbal own website so marketing becomes more widespread, 3) Both SMEs already have a simple bookkeeping, 4) Mentoring in both SMEs have been implemented, and 5) the assistance of both SMEs business development is gotten from the Ministry of Cooperation of the Republic of Indonesia.
\end{abstract}

Keywords: herbal products, marketing, websites

\begin{abstract}
ABSTRAK
Kegiatan ini dilakukan di UKM Lawu Herbal UKM di Mawar Street No 03. Dimoro RT 02 RW 10 Desa Karanganyar, Kecamatan Karanganyar dan UKM Pondok Daun di Rajawali Street No. 8, Ngebrak RT 01 / XI, Gentan, Baki, Sukoharjo. Kegiatan ini bertujuan untuk memberikan solusi dari masalah yang dihadapi oleh UKM. Masalah yang dihadapi oleh UKM Lawu Herbal adalah kemasan plastik sederhana masih menggunakan sistem sealer biasa; pemasaran masih terbatas dan tidak menggunakan media website. Masalahnya yang dihadapi oleh UKM Pondok Daun Herbal adalah tidak tersedianya pembukuan rapi. Kegiatan ini dilakukan oleh pengenalan alat vakum sealer, pelatihan pemasaran melalui website dan pelatihan akuntansi dan manajemen perbaikan keuangan.

Hasil dari kegiatan pelayanan adalah 1) kemasan produk di UKM Lawu Herbal menjadi lebih baik, lebih tahan lama dan segar, 2) UKM Lawu Herbal situs sendiri sehingga pemasaran menjadi lebih luas, 3) Kedua UKM sudah memiliki pembukuan sederhana, 4) Mentoring di kedua UKM telah dilaksanakan, dan 5) bantuan dari kedua UKM pengembangan bisnis didapat dari Kementerian Koperasi Republik Indonesia.
\end{abstract}

Kata kunci: produk herbal, pemasaran, website 


\section{PENDAHULUAN}

Rempah-rempah sudah ada di Indonesia sejak jaman dahulu kala. Rempahrempah tersebut menjadi daya tarik dan daya pikat bagi Bangsa Eropa untuk datang dan menjajah Indonesia.

Rempah-rempah yang terdiri dari berbagai jenis tanaman digunakan untuk menambah citarasa makanan, minuman. Namun selain itu juga dipercaya dapat digunakan untuk menjaga kesehatan, mencegah dan mengobati penyakit, dan sebagai bahan kecantikan (Qonita and Parnanto, 2015).

Pada saat ini rempah-rempah sudah banyak dikembangkan untuk produk herbal karena masyarakat percaya bahwa produk tersebut aman tanpa ada efek samping yang berbahaya bagi kesehatan tubuh. Produk herbal terbuat dari bahan-bahan alami tanaman atau tumbuhan tanpa campuran bahan kimia. Produk herbal bisa berupa makanan, minuman, obat-obatan maupun kosmetik.

Salah satu usaha produk herbal yang ada di Kabupaten Karanganyar adalah UKM Lawu Herbal milik Virnanto Hasmana Putra, A.Md, sedangkan di Kabupaten Sukoharjo adalah UKM Pondok Daun Herbal milik Sri Kuncoro. UKM Lawu Herbal didirikan pada tahun 2009 sebagai usaha perorangan atau pribadi. Jenis usaha yang dimiliki berupa olahan rempah, olahan coklat, kopi dan jamu godog. Produk yang dihasilkan adalah coklat tentrem, jamu 10 rasa, kopi mesra, wedang uwuh, rempah mandi, aneka masker wajah, aneka lulur badan. UKM yang kedua adalah UKM Pondok Daun Herbal. Pada awalnya usaha ini merupakan sebuah klinik herbal atau balai pengobatan herbal, yang secara langsung memberikan pelayanan kesehatan kepada masyarakat yang membutuhkan, dalam hal ini pasien yang membutuhkan pengobatan menggunakan tanaman obat atau herbal. UKM ini mulai membuat, mengolah, dan meramu produk herbal, yaitu Ca Sitosta, Koles.SS, Renalin, Vcap, Lakiwani, Enzimer,
Immuncap, Sirkulator, Itiser .SS, Paitan Super, Neuro. SS, Remat.SS, FresMovin, Tenser, Hemorrer, Aurcap, Ca Mix, Cerna.SS, Slimer, Mucova, Sehat napas, Uritan subur, Uritan resi, MoonCap, Batu. SS (Qonita dan Parnantoa, 2015).

Kedua UKM membuat produk herbal dari empon-empon maupun rempah-rempah yang berasal dari sekitar lokasi tempat usaha pemilik UKM. Kontinuitas bahan baku tersedia setiap saat karena ketersediaan di pasar relatif banyak. Selain itu ada beberapa jenis empon-empon dan rempah-rempah yang ditanam di sekitar tempat tinggal pemilik UKM. Misalnya untuk UKM Pondok Daun Herbal setiap bulannya membutuhkan paling tidak 50 jenis empon-empon / rempah-rempah dengan jumlah masing-masing sekitar $10 \mathrm{~kg}$ (Qonita dan Parnantob, 2015)..

Makna eksistensi usaha produk herbal yang diproduksi kedua UKM ini terhadap lingkungannya sangat tinggi. Usaha pembuatan produk herbal ini memberikan alternatif pengolahan empon-empon dan rempah-rempah tidak hanya menjadi jamu yang rasanya pahit dan tidak enak, tetapi menjadi produk yang enak dan praktis dikonsumsi serta bermanfaat bagi kesehatan tubuh, kecantikan, dan obat penyakit.

Permasalahan-permasalahan yang dihadapi oleh UKM tersebuat antara lain :

1. UKM Lawu Herbal masih menggunakan kemasan plastik sederhana, sehingga masih menyisakan udara dalam kemasan plastik, yang menyebabkan proses oksidasi alami yang menyebabkan proses pembusukan berjalan lebih cepat. Hal tersebut menyebabkan produk tidak fresh dan berbau tidak enak dan pada akhirnya menyebabkan produk tidak tahan lama.

2. Pemasaran UKM Lawu Herbal yang masih terbatas di Jawa Tengah dan DIY, belum dikenal di seluruh Indonesia.

3. Manajemen yang diterapkan oleh kedua UKM masih menggunakan manajemen 
sederhana, yaitu belum tersedianya sistem pembukuan yang rapi.

\section{Literature Review}

Indonesia merupakan negara yang kaya akan rempah-rempah. Rempah-rempah ini merupakan bahan tambahan yang tidak asing bagi masyarakat Indonesia (Sianipar et al, 2008).

Bahan rempah-rempah dapat dihasilkan dari umbi, biji, kulit batang,bunga, daun dan buah. Rempah-rempah yang merupakan umbi atau rimpang misalnya jahe, kunyit, temulawak, kencur, kunci, lengkuas atau laos, temu ireng dan lempuyang. Rempah yang berasal dari biji misalnya pala, kemiri, dan lain-lain. Kayu manis merupakan rempah yang berasal dari kulit batang. Rempahrempah yang berasal dari bunga misalnya cengkeh. Lada merupakan rempah yang berasal dari buah (Muchtadi dan Sugiyono, 1992).

Berdasarkan fungsinya, herbal dan rempah-rempah diklasifikasikan ke dalam bahan kuliner, kosmetik, dan farmasi. Pada jaman yang modern seperti sekarang, rempahrempah mempunyai tempat yang luas dalam seni kuliner di seluruh dunia, dan digunakan dalam industri pangan sebagai bahan penyedap dan bumbu, dan juga sebagai bahan farmasi untuk pengobatan dan perawatan kecantikan. Herbal dan rempah-rempah bermanfaat oleh karena bahan kimia yang terkandung dalam bentuk minyak atsiri, oleoresin, oleogum dan resin, yang memberi citarasa, rasa pedas dan warna terhadap makanan yang disajikan. Dari daftar the International Organization for Standardization (ISO) tercatat 112 jenis tanaman yang dikategorikan sebagai herbal dan rempahrempah. Diantara tanaman tersebut hanya sedikit jenis yang dibudidayakan dan dimanfaatkan secara komersial di berbagai negara, hanya sedikit dimanfaatkan namun sangat dikenal, sementara yang lainnya kurang dikenal, tumbuh sebagai tanaman liar dan belum dimanfaatkan. Herbal maupun rempah-rempah yang belum dimanfaatkan akan bernilai bukan hanya sebagai penyedap rasa, namun juga sebagai tanaman obat yang sangat penting (Antara dan Wartini, 2012).

\section{METODOLOGI PENELITIAN}

Metode yang digunakan untuk pemecahan masalah di atas adalah sebagai berikut (Qonita dan Parnantob, 2015).:

1. Sosialisasi. Kegiatan sosialisasi dimaksudkan untuk bersilaturahmi ke kedua UKM dan memberikan penjelasan tentang program-program dan kegiatan IbM yang akan dilakukan.

2. Perencanaan. Kegiatan perencanaan bertujuan untuk membuat jadwal pelaksanaan program kegiatan yang akan dilakukan, beserta apa saja yang harus dipersiapkan terkait dengan pelaksanaan kegiatan IbM. Juga tim pengabdi membuatkan suatu website yang berfungsi sebagai media yang bisa digunakan oleh UKM Lawu Herbal untuk melakukan pemasaran

3. Pelaksanaan. Pada tahap pelaksanaan tim pengabdi melakukan introduksi mesin vacuum sealer, pelatihan penggunaan website untuk sarana pemasaran dan pelatihan pembukuan sederhana.

4. Evaluasi. Kegiatan evaluasi digunakan untuk memantau kesesuaian antara rencana kegiatan yang telah dibuat dengan pelaksanaan yang dilakukan UKM Lawu Herbal dan UKM Pondok Daun Herbal

Solusi yang ditawarkan untuk mengatasi permasalahan yang dihadapi UKM Lawu Herbal dan UKM Pondok Daun Herbal adalah sebagai berikut :

1. Introduksi Vacuum Sealer untuk UKM Lawu Herbal

Selama ini UKM Lawu Herbal dalam mengemas produk herbalnya 
menggunakan plastik kemasan yang disealer dengan alat sealer biasa sehingga udara masih ada di dalam plastik yang bisa membuat produk tidak tahan lama, tidak fresh dan berbau tidak enak. Untuk itu proses pengemasan produk herbal perlu menggunakan vacuum sealer, sehingga udara yang ada di dalam kemasan bisa dihampakan dan terjadi proses dioksidasi, dan perkembangan oksigen akan ditekan sehingga bakteri akan berkembang biak dengan proses yang lama dibandingkan dengan sealer biasa. Hal tersebut akan membuat produk herbal lebih tahan lama, fresh dan terjaga kebersihannya.

2. Memberikan pelatihan pemasaran melalui internet untuk UKM Lawu Herbal

Pelatihan pemanfaatan internet sebagai media pemasaran produk herbal dilakukan dengan mengintroduksikan website untuk UKM Lawu Herbal. Setelah website sudah selesai dibuat dan telah siap untuk digunakan, maka pengusaha UKM Lawu Herbal diberi pelatihan cara pemasaran melalui website, cara pengelolaan dan cara meng-update materi dalam website. Beberapa pertimbangan mengintroduksikan website kepada UKM Lawu Herbal yaitu :

a. Dengan website, UKM Lawu Herbal dan produk yang dihasilkan akan dikenal luas, sehingga pemasarannya juga semakin luas.

b. Dengan website akan meningkatkan citra dan prestise bagi UKM Lawu Herbal, sehingga berpotensi meningkatkan penjualan.

c. Pengusaha UKM Lawu Herbal sudah familier dengan internet.
3. Perbaikan manajemen pembukuan di UKM Lawu Herbal dan UKM Pondok Daun Herbal

Perbaikan manajemen pembukuan pada di kedua UKM dengan pembukuan keuangan yang praktis yaitu model pembukuan keuangan sederhana yang mudah dipahami. Dengan pembukuan yang baik, maka UKM bisa mengontrol posisi keuangan sehingga pemborosan dan kerugian bisa diminimalisir. Untuk mengatasi kondisi tersebut perlu adanya solusi berupa pelatihan pembukuan praktis. Tim pengabdian akan melatih secara intensif pengusaha maupun karyawan UKM Pondok Daun Herbal dalam menyusun pembukuan praktis. Pelatihan pembukuan praktis dilakukan dengan tujuan agar UKM mampu mengidentifikasi komponen biaya baik biaya eksplisit (riil dikeluarkan) dan implisit (tidak riil dikeluarkan) serta menghitung keuntungan yang diperoleh. Selain itu dengan menyusun pembukuan yang benar, UKM Pondok Daun Herbal dapat mengetahui secara pasti besarnya keuntungan yang diperoleh sebagai sarana pengambilan keputusan untuk kegiatan produksi berikutnya dan sebagai dasar merencanakan pengembangan usaha.

\section{HASIL DAN PEMBAHASAN}

Tim pengabdian melakukan sosialisasi kegiatan yang akan dilaksanakan kepada kedua UKM mitra sesuai dengan ajuan kebutuhan.

Berikut foto kegiatan sosialisasi di kedua UKM mitra : 


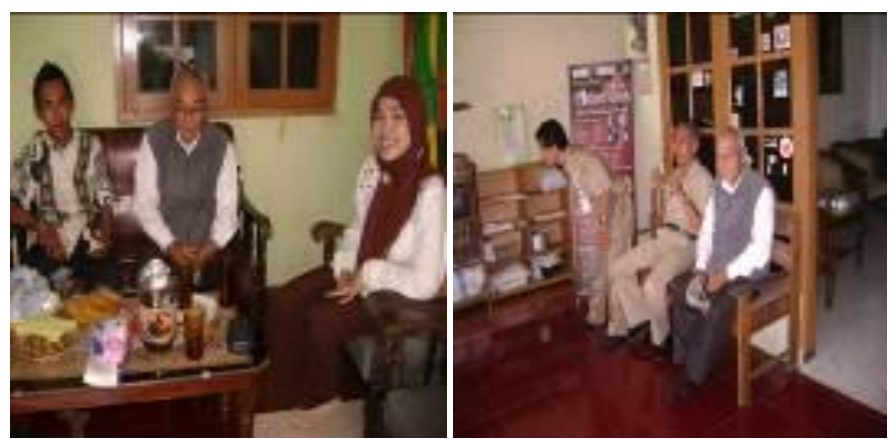

Gambar 1. Sosialisasi Kegiatan di UKM Lawu Herbal

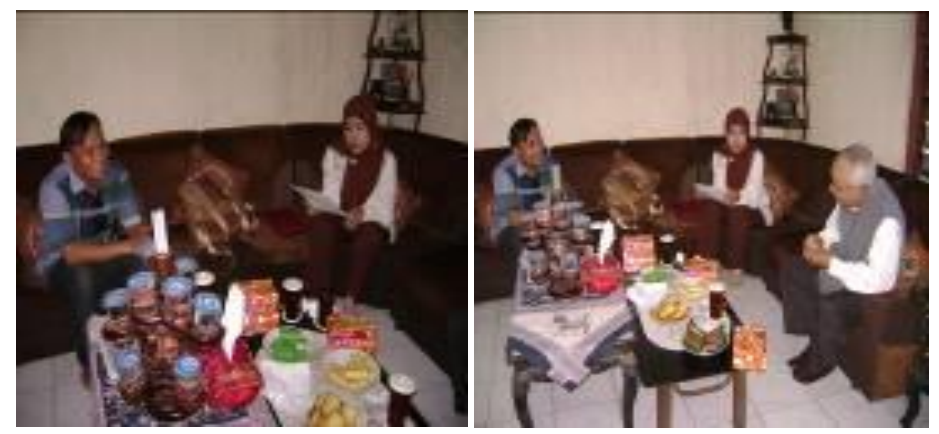

Gambar 2. Sosialisasi Kegiatan di UKM Pondok Daun

\section{Kegiatan-kegiatan yang telah dilaksanakan di kedua UKM mitra yaitu :}

\section{Introduksi Vacum Sealer di UKM Lawu Herbal}

Vacum sealer adalah alat pengemas vacum yang digunakan untuk menghisap udara yang ada dalam kemasan yang bertujuan untuk memperpanjang daya simpan produk. Tim memberikan cara memfungsikan/ menggunakan alat tersebut dengan baik. Karena cara dan merawat vacum sealer relatif mudah sehingga UKM mitra dengan mudah dapat menggunakannya. Proses introduksi vacum sealer sebagai berikut:

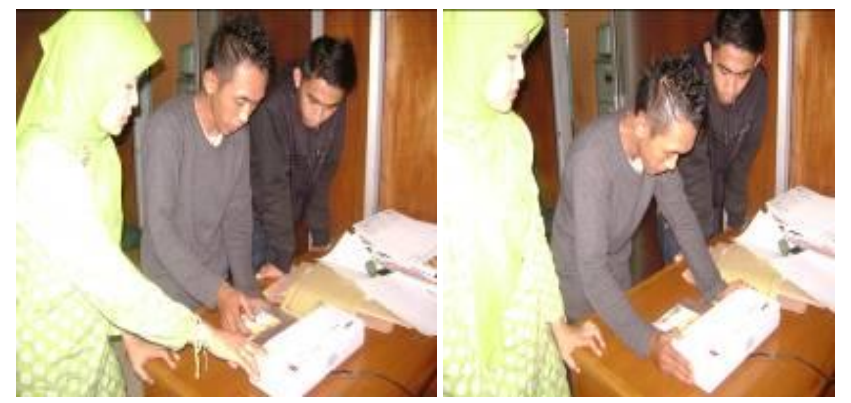

Gambar 3. Introduksi Vacum Sealer di UKM Lawu Herbal

UKM Lawu Herbal sudah menggunakan Vacum Sealer untuk mengemas produk yang dihasilkan. Metode penggunaan vacum sealer ini bertujuan untuk menghilangkan oksigen dari kemasan, sehingga menghambat pertumbuhan bakteri aerobik atau jamur dan mencegah penguapan. Dengan adanya vacum sealer akan membuat produk menjadi lebih awet, lebih tahan lama, tidak mudah berjamur. Gambar penggunaan Vacum Sealer dapat dilihat pada gambar berikut ini : 


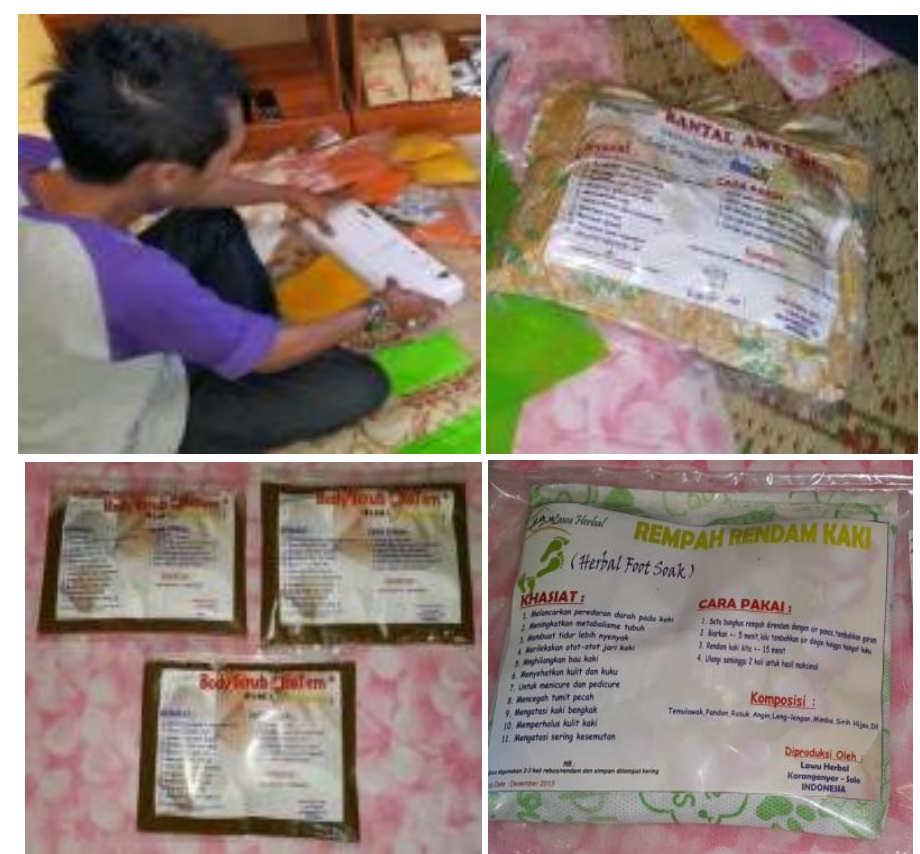

Gambar 4. Penggunaan Vacum Sealer di UKM Lawu Herbal

\section{Introduksi Pembuatan Website dan}

\section{Pelatihan Mengupdate Website}

Pemasaran didefinisikan sebagai telaah terhadap aliran produk secara fisis dan ekonomik, dari produsen melalui pedagang perantara ke konsumen (Downey dan Erickson, 1987). Pemasaran produk secara online sekarang ini banyak digunakan oleh para produsen ataupun reseller dalam memasarkan produk-produknya. Demikian juga halnya dengan UKM Lawu Herbal menginginkan pemasaran produk melalui website yang dapat dikelola sendiri sehingga masyarakat luas mengenal produk dan dapat membelinya secara online.

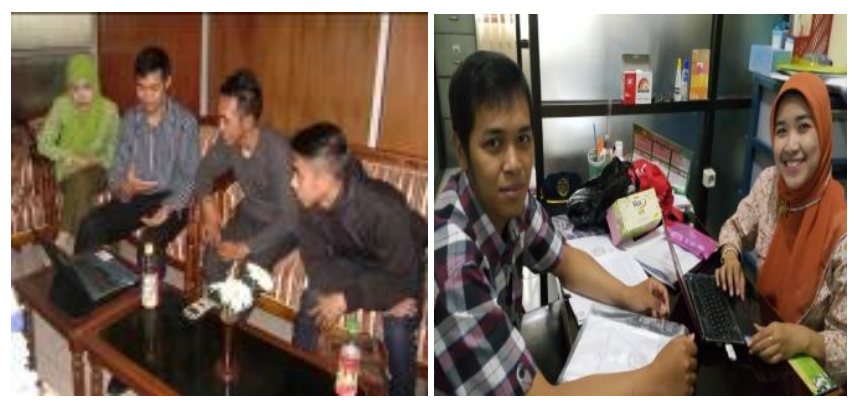

Pembuatan website didahului dengan Tim Pengabdian berdiskusi dengan UKM Lawu Herbal mengenai desain web, nama komersial web, isi/ kontain dalam website dan foto-foto produk yang akan diupload. UKM mitra diminta menampilkan foto produk yang baik untuk diupload. Setelah website selesai dibuat oleh Tim Pengabdian kemudian didiskusikan dengan UKM mitra. Proses diskusi selama mempersiapkan website dan pelatihan mengupdate website sebagai berikut: 


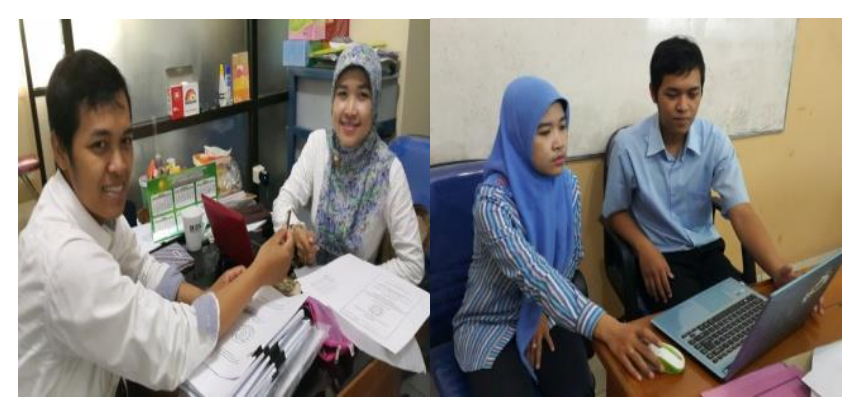

Gambar 5. Pembuatan dan Pelatihan Pembuatan Website di UKM Lawu Herbal

Alamat website adalah http://lawuherbal.com. Hasil pelatihan bagaimana mengupdate website, dapat dikuasai UKM mitra dengan cepat. UKM mitra dapat mempergunakan website ini selama 3 tahun dan setelahnya diharapkan mampu untuk membayar biaya perpanjangannya. Tampilan website sebagai berikut:

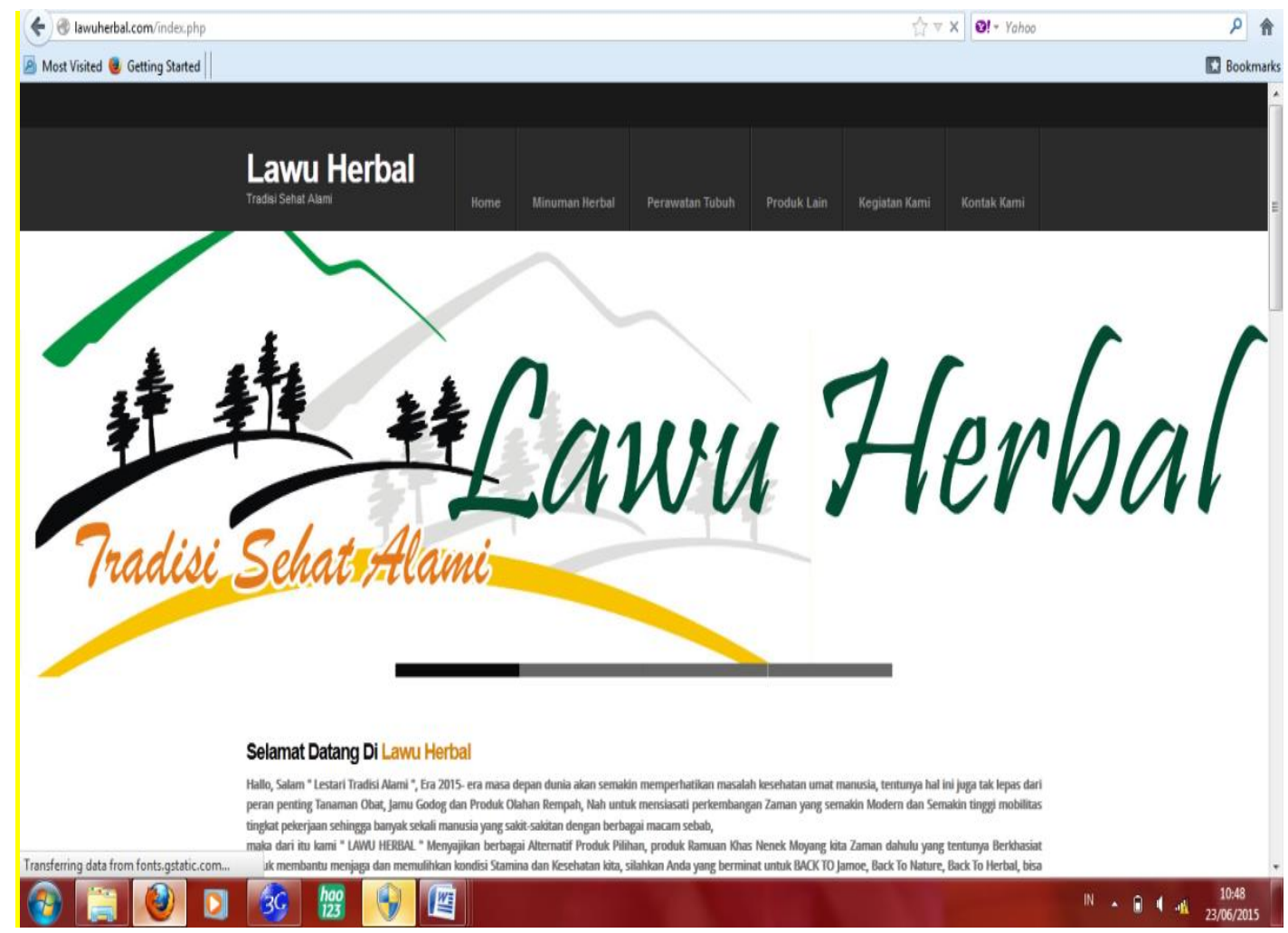

Gambar 6. Tampilan Website UKM Lawu Herbal

\section{Pelatihan Pembukuan Sederhana di Kedua UKM Mitra}

Selama ini kedua UKM mitra belum melakukan pembukuan usaha secara teratur, dimana pembukuan dilaksanakan jika terjadi transaksi penjualan maupun pembelian dalam jumlah besar saja. Tim Pengabdian memberikan arahan pentingnya melakukan pembukuan secara rutin sesuai dengan transaksi.
Pada dasarnya kedua UKM mitra dapat menyusun pembukuan sederhana, sehingga Tim Pengabdian lebih ringan dalam memberikan pelatihan. Kemauan, niat dan keinginan untuk memperbaiki pembukuan sangat dibutuhkan dalam proses pembukuan mulai dari pengumpulan nota/ kwitansi pembelian maupun penjualan dan menyalinnya ke dalam pembukuan sederhana. Pada tahap ini, kedua UKM mitra tidak 
menemui masalah yang berarti. Proses pelatihan pembukuan di kedua UKM sebagai

berikut:
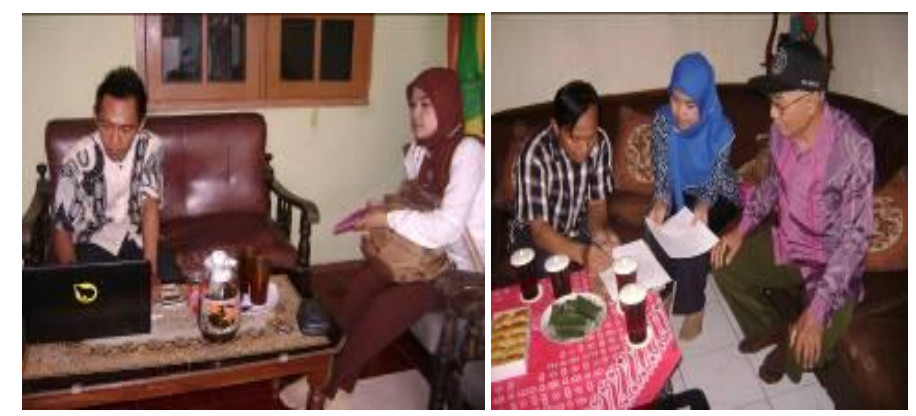

Gambar 7. Pelatihan Pembukuan Sederhana

di Kedua UKM

Hasil pelatihan pembukuan ini, UKM Lawu Herbal dan UKM Pondok Daun sudah mulai melakukan pembukuan pengeluaran dan penerimaan setiap harinya dengan mengumpulkan bukti-bukti transaksi hariannya. Proses pembukuan ini dimulai setelah berakhirnya pelatihan pembukuan. Sebenarnya tidak sulit untuk membukukan keuangan tetapi mengumpulkan bukti keuangan dan membukukannya dimana setiap hari dilakukan itu yang enggan dilakukan oleh kebanyakan UKM. Sampai sejauh ini, pembukuan sudah tertata dengan rapi dimana sudah ada kenaikan yang signifikan terhadap omset maupun laba usaha.

\section{Pendampingan di Kedua UKM}

Pendampingan kepada UKM Lawu Herbal dilakukan setelah introduksi peralatan, pelatihan pembukuan dan pembuatan website selesai dilakukan. Selain produk yang dipasarkan melalui website, UKM Lawu Herbal juga mempromosikan produknya melalui pembuatan katalog produk dan banner. Katalog produk dan banner ini sangat berguna bagi UKM jika UKM mengikuti event pameran baik yang difasilitasi oleh Dinas Koperasi Kabupaten Karanganyar, Pusat Studi Pendampingan Koperasi dan UMKM LPPM UNS, HIPMI Karanganyar/ Kota Solo maupun mandiri. Katalog produk dan banner yang dimiliki oleh UKM Lawu Herbal sebagai berikut:
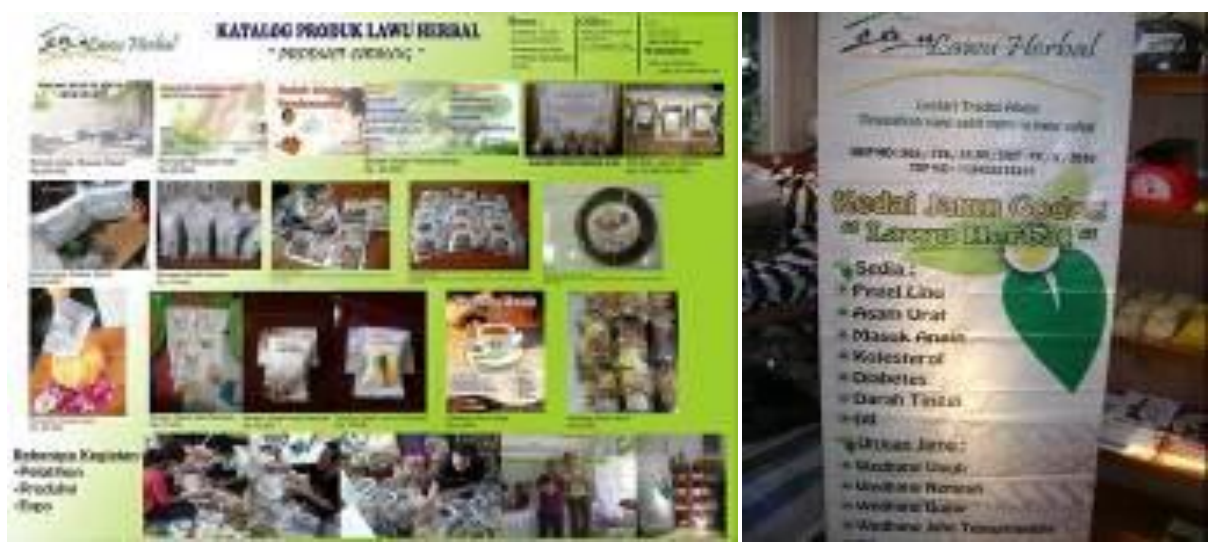

Gambar 8. Katalog dan Banner UKM Lawu Herbal

Hasil introduksi peralatan dan pelatihan di UKM Lawu Herbal dapat menyebabkan terjadi perluasan pemasaran dimana produk rempah mandi, rempah rendam kaki, bantal 
lelap dan kopi mesra kemasan cangkir secara kontinue dipasarkan ke Mirota Batik Yogyakarta, Mirota Kaliurang Yogyakarta dan Pasar Seni Nadzar Yogyakarta.

Juga pada tanggal 20 Oktober, UKM Lawu Herbal mengikuti acara "Lawu Fair" di
Kabupaten Karanganyar. Dilihat dari pembukuan di UKM Lawu Herbal dapat diketahui bahwa terjadi kenaikan produksi, omset penjualan dan keuntungan UKM. Hal ini dapat dilihat pada tabel berikut :

Tabel 1. Rata-rata Produksi, Omset Penjualan dan Keuntungan

UKM Lawu Herbal per Bulan

\begin{tabular}{|l|l|l|l|}
\hline Indikator & Produk & Sebelum Program IbM & Sesudah Program IbM \\
\hline \multirow{3}{*}{ Produksi } & Rempah Mandi & 200 pack & 400 pack \\
\cline { 2 - 4 } & Rendam Kaki & 200 pack & 400 pack \\
\cline { 2 - 4 } & Bantal Lelap & 200 pack & 400 pack \\
\hline Omset & & Rp 6.600.000 & Rp 13.200.000 \\
\hline Keuntungan Total & & Rp $1.800 .000-$ Rp 2.000.000 & Rp 5.000.000 \\
\hline
\end{tabular}

Sumber : Data Primer, 2015

Berdasarkan tabel di atas diketahui bahwa terjadi kenaikan produksi di UKM Lawu Herbal meningkat $100 \%$, terutama untuk 3 produk best seller yaitu rempah mandi, rendam kaki, bantal lelap. Kenaikan produksi ini lebih dikarenakan permintaan dan pangsa pasar produk UKM Lawu Herbal semakin luas, sehingga produksinya menyesuaikan kondisi yang ada. Selain itu terjadi kenaikan produksi sebesar 100\%, omset penjualan sebesar $100 \%$ dan keuntungan sebesar $100 \%$.

Pemasaran produk di UKM Pondok Daun dilakukan dengan menggunakan katalog produk yang menampilkan lebih dari 25 jenis produk. Katalog produk tersebut sangat membantu konsumen dalam mengetahui isi dan kegunaan produk herbal apakah sesuai dengan kebutuhannya atau tidak. Pemasaran produk UKM Pondok Daun lebih banyak di Pondok Pesantren baik di Kota Solo, Kabupaten Sukoharjo dan Kabupaten Karanganyar. Selain itu, pada tahap sekarang ini telah dirintis sebagai supllier bahan baku herbal ke perusahaan produk herbal yang lebih besar kapasitas produksinya.

Dilihat dari pembukuan di UKM Pondok Daun dapat diketahui bahwa terjadi kenaikan produksi, omset penjualan dan keuntungan UKM. Hal ini dapat dilihat pada tabel berikut :

Tabel 4. Rata-rata Produksi, Omset Penjualan dan Keuntungan

UKM Pondok Daun Herbal per Bulan

\begin{tabular}{|l|c|c|}
\hline \multicolumn{1}{|c|}{ Indikator } & $\begin{array}{c}\text { Sebelum Program } \\
\mathrm{IbM}\end{array}$ & $\begin{array}{c}\text { Sesudah Program } \\
\mathrm{IbM}\end{array}$ \\
\hline Produksi & 750 botol & 1.000 botol \\
\hline Omset & $\mathrm{Rp} 15.000 .000$ & $\mathrm{Rp} 20.000 .000$ \\
\hline Keuntungan & $\mathrm{Rp} \mathrm{7.500.000}$ & $\mathrm{Rp} 10.500 .000$ \\
\hline
\end{tabular}

Sumber : Data Primer, 2015

Berdasarkan tabel di atas diketahui bahwa terjadi kenaikan produksi di UKM
Pondok Daun Herbal. Kenaikan produksi ini lebih dikarenakan permintaan dan pangsa 
pasar produk UKM Pondok Daun semakin luas, sehingga produksinya menyesuaikan kondisi yang ada. Tabel juga menunjukkan bahwa terjadi kenaikan produksi sebesar 25\%, omset penjualan meningkat sebesar $25 \%$ dan keuntungan meningkat sebesar $28 \%$, sehingga dapat dikatakan bahwa target luaran program IbM ini dapat dicapai.

Pendampingan yang dilakukan oleh Tim Pengabdi bersifat memberdayakan UKM Lawu Herbal dan UKM Pondok Daun. Tim Pengabdian bertugas mengarahkan pencapaian hasil dan kedua UKM diminta dapat mandiri sehingga tidak menimbulkan ketergantungan. Dengan demikian diharapkan hasil pendampingan, dapat meningkatkan kinerja yang cukup berarti bagi kedua UKM dan memberikan manfaat bagi pengembangan usaha herbal.

\section{Perbaikan Manajemen}

Perbaikan manajemen dilakukan dengan cara mendaftarkan kedua UKM untuk mengikuti Pelatihan Kewirausahaan dan Penyusunan Bussines Plan yang diselenggarakan oleh Pusat Studi Pendampingan Koperasi dan UMKM LPPM UNS yang bekerja sama dengan Kementrian Koperasi Republik Indonesia. Di dalam pengajuan proposal kedua UKM mendapatkan bantuan pengembangan usaha sebesar Rp 22.000.000 untuk UKM Pondok Daun dan Rp 18.000.000 untuk UKM Lawu Herbal. Dengan adanya bantuan dana pengembangan usaha ini diharapkan kedua UKM dapat mempergunakan sebaik mungkin untuk bisa lebih meningkatkan usahanya agar semakin besar. Berikut ini gambar kedua UKM ketika mengikuti pelatihan.

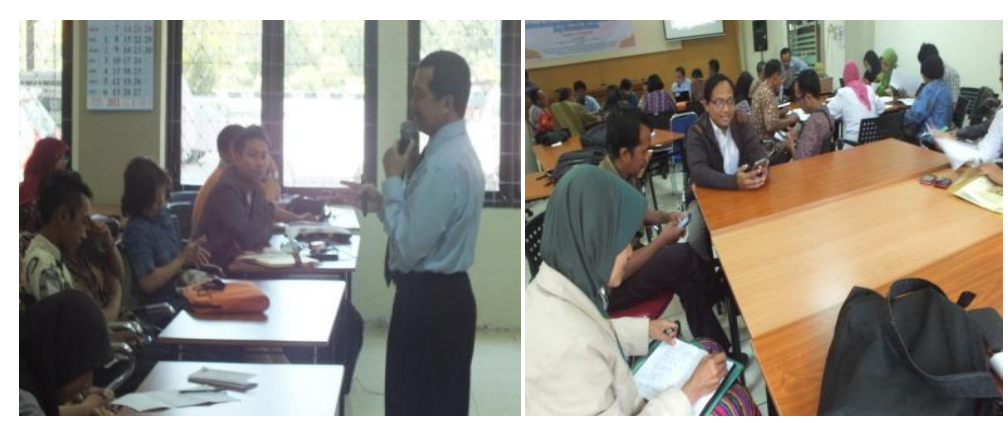

Gambar 9. Kedua UKM Mengikuti Pelatihan Kewirausahaan dan Penyusunan Bussines Plan

\section{KESIMPULAN}

Kegiatan yang telah dilaksanakan dalam program IbM ini menjawab permasalahan aktual yang terjadi pada saat ini. Kegiatankegiatan yang telah dilaksanakan di kedua UKM mitra yaitu 1) introduksi vacum sealer di UKM Lawu Herbal, 2) introduksi pembuatan website dan pelatihan mengupdate website, 3) pelatihan pembukuan sederhana di kedua UKM mitra, 4) pendampingan di kedua UKM, serta 5) perbaikan manajemen di kedua UKM.

Kegiatan yang telah dilaksanakan perlu pendampingan secara kontinue terutama pada proses pembukuan sederhana dan perluasan jaringan pemasarannya. Pendampingan ini sifatnya memberdayakan sehingga UKM dituntut untuk dapat mandiri dalam berusaha sehingga lambat laun harus dikurangi namun tetap dalam monitoring.

\section{DAFTAR PUSTAKA}

Antara, N.S. dan Wartini, M. 2012. Senyawa Aroma dan Citarasa (Aroma And Flavor Compounds). Tropical Plant Curriculum Project. Udayana University.

Downey, W.D. dan Erickson, S.P. Manajemen Agribisnis. Erlangga. Jakarta 
Muchtadi, T.R. dan Sugiyono. 1992. Petunjuk Laboratorium Ilmu pengetahuan Bahan. Pusat Antar Universitas pangan dan Gizi Institut Pertanian Bogor. Bogor.

Sianipar, D., Sugiyono dan Syarief, R. 2008. Kajian Formulasi Bumbu Instan Binthe Biluhuta, Karakteristik Hidratasi dan Pendugaan Umur Simpannya Dengan Menggunakan Metode Pendekatan Kadar Air Kritis. Jurnal Teknologi dan Industri Pangan. Vol. XIX No. 1. 2008.

Qonita, A dan Parnanto, $\mathrm{NH}^{\mathrm{a}}$. 2015. Aplikasi Mesin penepung Bahan Herbal untuk Meningkatkan Efisiensi Produksi pada Skala Home Industri. Prosiding Seminar Nasional Integritas Pengembangan UMKM dalam Masyarakat Ekonomi Asean (MEA). Pusat Studi Pendampingan Koperasi dan UMKM Lembaga Penelitian dan Pengabdian Kepada Masyarakat Universitas Sebelas Maret. Surakarta tanggal 30 Juli 2015.

b. 2015. Laporan Akhir Ipteks Bagi Masyarakat. Lembaga Penelitian dan Pengabdian Kepada Masyarakat Universitas Sebelas Maret. Surakarta. 